\title{
Impacts of single nucleotide polymorphisms and haplotypes in the bovine Dapper1 gene on body weight
}

\author{
J. Wang ${ }^{1}$, C. Wang ${ }^{1}$, Y. Gao ${ }^{1}$, X.-Y. Lan ${ }^{1}$, C.-Z. Lei ${ }^{1}$, J.-Q. Wang ${ }^{2}$ and \\ H. Chen ${ }^{1}$ \\ ${ }^{1}$ Shaanxi Key Laboratory of Molecular Biology for Agriculture, \\ College of Animal Science and Technology, \\ Northwest A\&F University, Yangling, Shaanxi, China \\ ${ }^{2}$ Research Center of Cattle Engineering Technology in Henan, \\ Zhengzhou, Henan, China \\ Corresponding author: H. Chen \\ E-mail: chenhong1212@263.net
}

Genet. Mol. Res. 12 (2): 1254-1268 (2013)

Received July 30, 2012

Accepted January 30, 2013

Published April 17, 2013

DOI http://dx.doi.org/10.4238/2013.April.17.4

\begin{abstract}
The Dapper1 protein plays important role in multiple developmental processes via negative modulation of the Wnt signaling pathway. We detected variations in Dapper1 in 1185 individuals from 5 Chinese cattle breeds and determined their effects on bovine body weight. Two silent mutations (g.8344C $>\mathrm{T}$ and g.8428C $>$ T) in exon 6 along with two substitutions (g.10513A $>$ G and $\mathrm{g} .10765 \mathrm{C}>\mathrm{G}$ ) in the $3^{\prime}$-untranslated region were detected with DNA pool sequencing and forced polymerase chain reactionrestriction fragment length polymorphism. Haplotype variability and the extent of linkage disequilibrium of the 4 single nucleotide polymorphisms (SNPs) were analyzed, and the results revealed 16 haplotypes and 7 combined haplotypes in the 5 cattle breeds. Statistical analyses indicated that genotypes $\mathrm{CC}$ and $\mathrm{AA}$ in the g.8344C $>$ T and g.10513A $>$ G loci were associated with heavier body
\end{abstract}


weight at 6 months in the Nanyang cattle population $(\mathrm{P}<0.05)$, and the combined haplotype had consistent significant effects on body weight with a single SNP. Cattle with haplotype combinations H1H5 (CCCTAACC) displayed the heaviest body weight at 6 months compared with that of other haplotypes $(\mathrm{P}<0.05)$. Our results provide evidence that 4 SNPs and haplotypes in Dapper 1 may be used for marker-assisted selection in beef cattle breeding programs.

Key words: Cattle; Dapper 1 gene; SNPs; Haplotype; F-PCR-RFLP; Body weight

\section{INTRODUCTION}

The Wnt signaling pathway includes canonical (Wnt/ $\beta$-catenin) (Cerpa et al., 2009; Tee et al., 2009; Fukuda et al., 2010) and noncanonical (Wnt/planar cell polarity pathway and $\mathrm{Wnt} / \mathrm{Ca}^{2+}$ channel) (Dale et al., 2009) pathways. The signaling pathway plays an important role in embryogenesis by regulating the expression of genes involved in cell proliferation, differentiation, and survival (Gao et al., 2008). The pathway also acts as a molecular switch that governs adipogenesis, which maintains preadipocytes in an undifferentiated state through the inhibition of adipogenic transcription factors (Kawai et al., 2007).

The Dapper family, originally identified as a Dvl-interacting protein, has been shown to inhibit both Dvl-mediated canonical and noncanonical Wnt pathways and is required for formation of the notochord and head structures in Xenopus embryos (Cheyette et al., 2002; Gloy et al., 2002). The Dapper family has three orthologs, Dapper 1, Dapper2, and Dapper3 (Katoh and Katoh, 2003; Waxman et al., 2004; Fisher et al., 2006; Zhang et al., 2006), which are conserved in the N-terminal leucine zipper and the C-terminal serine-rich domain. The functions of the ortholog proteins are conserved from fish to mammals (Zhang et al., 2006; Su et al., 2007).

The zebrafish Dapper1 gene participates in distinct Wnt-dependent developmental processes (Waxman et al., 2004). The Dapper 1 protein plays a regulatory role in embryonic and adult tissues by modulating Wnt signaling and transforming growth factor-beta signaling. Computer analysis has predicted that both Dapper 1 and Dapper 2 are involved in the formation of certain tumors (Katoh and Katoh, 2003). Mammalian Dapperl inhibits the expression of the Wnt-responsive reporters lymphoid enhancer factor-luciferase and TOPFLASH-luciferase. Considering its role in the Wnt pathway, which is important for embryogenesis, tissue homeostasis, and adipogenesis in adults (Gao et al., 2008), Dapper 1 seems to be a functional candidate gene associated with embryo development, lipid metabolism, and tumor formation, thereby affecting bovine growth performance traits such as survival rate, health status, energy intake, and body weight. However, few studies have investigated the genetic variants and function of bovine Dapper 1 .

In this study, we systematically screened the mutations in all exons, including partial introns and the 3'-untranslated region (UTR) of Dapper 1 in 5 Chinese cattle breeds with DNA pool sequencing. We then genotyped the allele frequencies using forced-polymerase chain reaction-restriction fragment length polymorphism (F-PCR-RFLP) to evaluate genetic diversity, haplotype variability, and the extent of linkage disequilibrium (LD). 
In the Nanyang breed, we tested the effects of these variants on BW, which may contribute to advances in animal breeding and genetics.

\section{MATERIAL AND METHODS}

\section{DNA samples and data collection}

All procedures involving animals were approved by the Animal Care and Use Committee at the institution at which the experiment was conducted. Blood samples of 1185 unrelated female cattle were obtained from 5 breeds of Chinese bovine: Jiaxian red (JX, $\mathrm{N}=355$ ), Chinese Caoyuan red ( $\mathrm{CY}, \mathrm{N}=235)$, Qinchuan (QC, $\mathrm{N}=216)$, Nanyang ( $\mathrm{NY}, \mathrm{N}=213$ ), and Luxi (LX, $N=166)$. These breeds are important for beef production in China and are reared in the Provinces of Henan, Jilin, Shaanxi, and Shandong. The JX animals were from a breeding farm of JX cattle (Jiaxian county, Henan Province, China); the CY animals were from a breeding farm of CY red cattle (Tongyu city, Jilin Province); the QC animals were from a breeding farm and fineness breeding center of QC cattle (Fufeng county, Shaanxi Province); the NY animals were from a breeding farm of NY cattle (Nanyang city, Henan Province); and the LX animals were from a reserved farm (Juancheng county and Jining city, Shandong Province).

Blood samples were obtained via jugular venipuncture using vacuum tubes treated with $0.25 \%$ ethylenediaminetetraacetic acid. Genomic DNA were isolated from blood samples following a procedure published by Mullenbach et al. (1989) and stored at $-80^{\circ} \mathrm{C}$. Additionally, we quantified the body weight (BW) of $213 \mathrm{NY}$ animals. These animals were weaned at an average age of 6 months and were fed a corn-corn silage diet from weaning to slaughter, and straw at 24 months of age. The traits under study were BW at birth, 6 months (BW6), 12 months (BW12), 18 months (BW18), and 24 months (BW24).

\section{Primer design, PCR amplification, and DNA pool analysis}

Seven pairs of PCR primers (P1-P7; see Table 1) were designed to amplify all exons (1-6) and the 3'-UTR of bovine Dapper1 (GenBank accession No. NC_007308.4), including its intron-exon boundaries and the proximal flanking regions.

The $25-\mu \mathrm{L}$ PCR volume contained $50 \mathrm{ng}$ genomic DNA, $0.5 \mu \mathrm{M}$ of each primer, $1 \mathrm{X}$ buffer (including $1.5 \mathrm{mM} \mathrm{MgCl}_{2}$ ), $200 \mu \mathrm{M}$ deoxyribonucleotide triphosphates (2'-deoxyadenosine triphosphate, 2'-deoxythymidine triphosphate, 2'-deoxycytidine 5'-triphosphate, and 2'-deoxyguanosine 5'-triphosphate) and $0.625 \mathrm{U} \mathrm{Taq}$ DNA polymerase (MBI, Vilnius, Lithuania). The cycling protocol was $5 \mathrm{~min}$ at $95^{\circ} \mathrm{C}, 34$ cycles of $94^{\circ} \mathrm{C}$ for $30 \mathrm{~s}$, annealing for $30 \mathrm{~s}$, and $72^{\circ} \mathrm{C}$ for $35 \mathrm{~s}$ (see Table 1), with a final extension at $72^{\circ} \mathrm{C}$ for $10 \mathrm{~min}$.

Fifty DNA samples from each of the 5 cattle breeds were selected to construct DNA pools. The selected DNA was diluted to a standard concentration, and individual DNA aliquots were transferred to a single tube to ensure that a constant amount of each sample was transferred to the pool. The pool was then mixed gently and quantitated before further dilution to a working concentration of $50 \mathrm{ng} / \mu \mathrm{L}$. After amplifying the bovine genomic DNA pool (Sham et al., 2002), we sequenced PCR products using an ABI PRISM 377 DNA sequencer (Shanghai Sangon Biotech Co., Ltd., P.R. China) and then analyzed them with the BioXM version 2.6 software. 


\begin{tabular}{|c|c|c|c|c|c|c|c|}
\hline Loci & $\begin{array}{c}\text { Position } \\
\text { NC_007308.4 }\end{array}$ & Sequence $\left(5^{\prime}-3^{\prime}\right)^{*}$ & $\begin{array}{c}\mathrm{Ta} \\
\left({ }^{\circ} \mathrm{C}\right)\end{array}$ & $\begin{array}{l}\text { SAF } \\
(\mathrm{bp})\end{array}$ & $\begin{array}{l}\text { Restriction } \\
\text { enzyme }\end{array}$ & Location & $\begin{array}{l}\text { PCR-RFLP } \\
\text { pattern (bp) }\end{array}$ \\
\hline P1 & $1-177$ & $\begin{array}{l}\text { F: ATGGTGGGCTGCAACTCGGTC } \\
\text { R: CACCCAGTTTTTGCCTCGCTTC }\end{array}$ & 62 & 177 & & Exon 1 & \\
\hline P2 & $386-580$ & $\begin{array}{l}\text { F: CGCCGGGCAGGGCGTTATCAG } \\
\text { R: AGGAGCGGGCGCTAGGGCTG }\end{array}$ & 58 & 195 & & Exon 2 & \\
\hline P3 & $619-1065$ & $\begin{array}{l}\text { F: GACCGGGTTGAGGGCCATGAAG } \\
\text { R: TAGAGGCACCCACCACGGACCAC }\end{array}$ & 60 & 447 & & Exon 3 & \\
\hline P4 & $3156-3446$ & $\begin{array}{l}\text { F: CCTTTCTCTGTTTCTTCCTCATC } \\
\text { R: TGTCTTGTTTTGCTGTAGTCTCTC }\end{array}$ & 64 & 291 & & Exon 4 & \\
\hline P5 & $4136-4725$ & $\begin{array}{l}\text { F: GGGTCAAGGAGGAAGGTCA } \\
\text { R: TAGAAGGGTGGGATGGTGT }\end{array}$ & 59 & 590 & & Exon 5 & \\
\hline P6 & $8231-8869$ & $\begin{array}{l}\text { F: ACACCACAATCTAATTCCCTTGC } \\
\text { R: CTTACCTTGAAGTTCGGTAGCAG }\end{array}$ & 66 & 639 & & Exon 6 & \\
\hline P7 & $10266-10934$ & $\begin{array}{l}\text { F: GGTGGTGACAGTGAGTGGA } \\
\text { R: TTGGGCTAATGTTTAGATGG }\end{array}$ & 65 & 669 & & artial 3'-UTR & \\
\hline $\begin{array}{l}\text { P8 } \\
\text { (g.8344C }>\mathrm{T})\end{array}$ & $8213-8371$ & $\begin{array}{l}\text { F: GTTGACTGTTCCCCCTCCACACCAC } \\
\text { R: GAGGAACATTGGGCTCTGCACGGCC } \underline{\mathbf{C}}\end{array}$ & 64 & 159 & $\begin{array}{c}M s p \mathrm{I} \\
\mathrm{C}^{\wedge} \mathrm{CGG}\end{array}$ & Exon 6 & $\begin{array}{c}\text { TT: } 159 \\
\text { CT: } 159,131,28 \\
\text { CC: } 131,28\end{array}$ \\
\hline $\begin{array}{l}\text { P9 } \\
(\mathrm{g} .8428 \mathrm{C}>\mathrm{T})\end{array}$ & $8402-8612$ & $\begin{array}{l}\text { F: GAGGAGCGGCTTGGTAACCATGTTAA } \\
\text { R: CAGCGTTCACACTGGTCCTCGG }\end{array}$ & 66 & 211 & $\begin{array}{c}H i n d I I \\
\text { GTT^AAC }^{\wedge}\end{array}$ & Exon 6 & $\begin{array}{c}\text { TT: } 211 \\
\text { CT: } 211,187,24 \\
\text { CC: } 187,24\end{array}$ \\
\hline $\begin{array}{l}\text { P10 } \\
(\text { g. } 10513 \mathrm{~A}>\mathrm{G})\end{array}$ & $10488-10693$ & $\begin{array}{l}\text { F: TGTGAAGCAGATACAAGGGGCAGCC } \\
\text { R: GTGGCAAAGGTTTTAGCGAATCC }\end{array}$ & 63 & 206 & $\begin{array}{c}N c o \mathrm{I} \\
\mathrm{C}^{\wedge} \mathrm{CATGG}\end{array}$ & 3'-UTR & $\begin{array}{l}\text { GG: } 206 \\
\text { AG: } 206,183,23 \\
\text { AA: } 183,23\end{array}$ \\
\hline $\begin{array}{l}\text { P11 } \\
\text { (g.10765C }>\text { G) }\end{array}$ & 10740-10981 & $\begin{array}{l}\text { F: TACCCAACATTGATGCCTTTTTCGC } \\
\text { R: CAAGACAGGGTCAGTGGTCCAATC }\end{array}$ & 65 & 242 & $\begin{array}{c}H h a \mathrm{I} \\
\mathrm{GCG}^{\wedge} \mathrm{C}\end{array}$ & 3'-UTR & $\begin{array}{c}\text { CC: } 242 \\
\text { CG: } 242,219,23 \\
\text { GG: } 219,23\end{array}$ \\
\hline
\end{tabular}

Primers P1-P7 were used to amplify the different exons and 3'-UTR of the bovine Dapper1 gene to detected the mutations. The last 4 pairs of primers (P8-P11) were used for detection of the 4 SNPs in the bovine Dapperl gene. Ta $=$ annealing temperature; $\mathrm{SAF}=$ size of amplification fragment. ${ }^{*}$ Nucleotides that are in bold stand for the naturally occurring nucleotides that were substituted with primers (P8-R, P9-F, P10-F, P11-F) to introduce a new recognition restriction endonuclease site. Underlined nucleotides mark recognition sites for the restriction endonuclease.

\section{F-PCR-RFLP}

F-PCR-RFLP was used to detect polymorphism sites, which introduced a point mutation into one of the primer sequences so that the PCR product contained a restriction endonuclease recognition site. Four pairs of new primers (P8-P11; see Table 1) were designed to detect four mutations through F-PCR-RFLP. Primers, selected restriction enzymes (MBI Fermentas, Vilnius, Lithuania), and fragment sizes are given in Table 1.

Aliquots of $10 \mu \mathrm{L}$ PCR products were digested with $10 \mathrm{U}$ MspI, HindII, NcoI, and HhaI for $8 \mathrm{~h}$ at $37^{\circ} \mathrm{C}$, following supplier instructions. The digested products were detected with electrophoresis on $2.5 \%$ agarose gel stained with ethidium bromide. The detection results of genotypic variation at the SNPs were based on the electrophoretic pattern of the restriction enzyme-treated PCR products.

\section{Statistical analysis}

Genotypic and allelic frequencies of polymorphism sites in bovine Dapper1 among Chinese cattle populations were analyzed using the chi-square test performed with the SPSS version 18.0 
software. Gene homozygosity $\left(H_{\mathrm{O}}\right)$, heterozygosity $\left(H_{\mathrm{E}}\right)$, effective allele numbers $\left(N_{\mathrm{E}}\right)$, and polymorphism information content (PIC) were evaluated using Nei's methods (Nei and Roychoudhury, 1974).

The LD structure determination was performed with the HAPLOVIEW version 3.32 software (Barrett et al., 2005), which measured $D^{\prime}$ and $r^{2}$. Some research has shown that $r^{2}$ is not as sensitive as $D^{\prime}$ to allele frequencies; therefore, $r^{2}$ was used as a pairwise measure of LD in our analysis (Zhao et al., 2007; Marty et al., 2010). Haplotypes were obtained for each animal using the PHASE version 2.1 computer program (Stephens et al., 2001). Association of individual SNP genotypes with BW in NY cattle were analyzed with the general linear model using SPSS version 16.0 according to the following equation:

$$
Y_{i j k}=\mu+A_{i}+G_{j}+E_{i j k},
$$

where $Y_{i j k}$ is the trait measured on each $i j k^{\text {th }}$ animal; $\mu$ is the overall population mean; $A_{i}$ is the fixed effect due to the $i^{\text {th }}$ age; $G_{j}$ is the fixed effect associated with the $j^{\text {th }}$ genotype; and $E_{i j k}$ is the random error. In this model, age and marker genotypes were considered fixed effects; dam (litter), a random effect; and $\mathrm{BW}$, the dependent variable.

Association analyses between the combined haplotypes of four SNPs and BW were carried out to explore the possible interaction between the SNPs. The model was similar to that of individual SNP association analysis except that the interaction between two SNPs was included as a fixed effect.

\section{RESULTS}

\section{SNP detection in bovine Dapper1}

Bovine Dapper 1 was located at chromosome 10, encoding 907 amino acids (aa) that included 6 exons. In the present study, polymorphisms of all the exons, partial introns, and the 3'-UTR in bovine Dapperl were identified through DNA pool sequencing. Four SNPs were identified; two in exon 6 (NC_007308.4: g.8344C $>$ T, g.8428C $>$ T) and two in the 3'-UTR (g.10513A >G, g.10765C $>$ G; Figures 1-4). The former two SNPs revealed two synonymous mutations: the g.8344C $>$ T mutation GCC (Ala) $>$ GCT (Ala) at position 340 aa and the g.8428C $>$ T mutation AAC (Asn) $>$ AAT (Asn) at position 368 aa. These four SNPs were novel and were deposited in the GenBank database (Table 2).

F-PCR-RFLP was successfully applied to detect the genotypic frequency of these Dapper 1 SNPs in 5 Chinese cattle breeds, and these SNPs were named according to the restriction endonuclease used in the detection: SNP1-MspI locus (g.8344C $>$ T), SNP2-HindII locus (g.8428C>T), SNP3-NcoI (g.10513A>G), and SNP4-HhaI locus (g.10765C >G).

\section{Genetic diversity analysis}

The genotype and allele frequencies, $H_{\mathrm{O}}, H_{\mathrm{E}}, N_{\mathrm{E}}$, and PIC were evaluated in the 5 Chinese cattle populations (Table 3). For the SNP1-MspI, SNP2-HindII, and SNP3-NcoI loci, the frequencies of alleles T, C, and G were higher than those of other alleles in JX, QC, NY, and LX cattle. On the contrary, in CY cattle, the frequencies of alleles C, T, and A were higher in these three loci. At the last locus (SNP4-HhaI), the frequency of allele $\mathrm{C}$ was highest in all five 
breeds. The values of $H_{\mathrm{E}}$ approached 0.5 at the SNP1-MspI and SNP3-NcoI loci; in the SNP2HindII locus, only JX cattle displayed a lower $H_{\mathrm{E}}$ value (0.280), and in the SNP4-HhaI locus, CY cattle had the lowest $H_{\mathrm{E}}$ value (0.070). The values of $N_{\mathrm{E}}$ approached 2 in all five breeds, except in CY cattle in which the value at the SNP4-HhaI locus was 1.075.
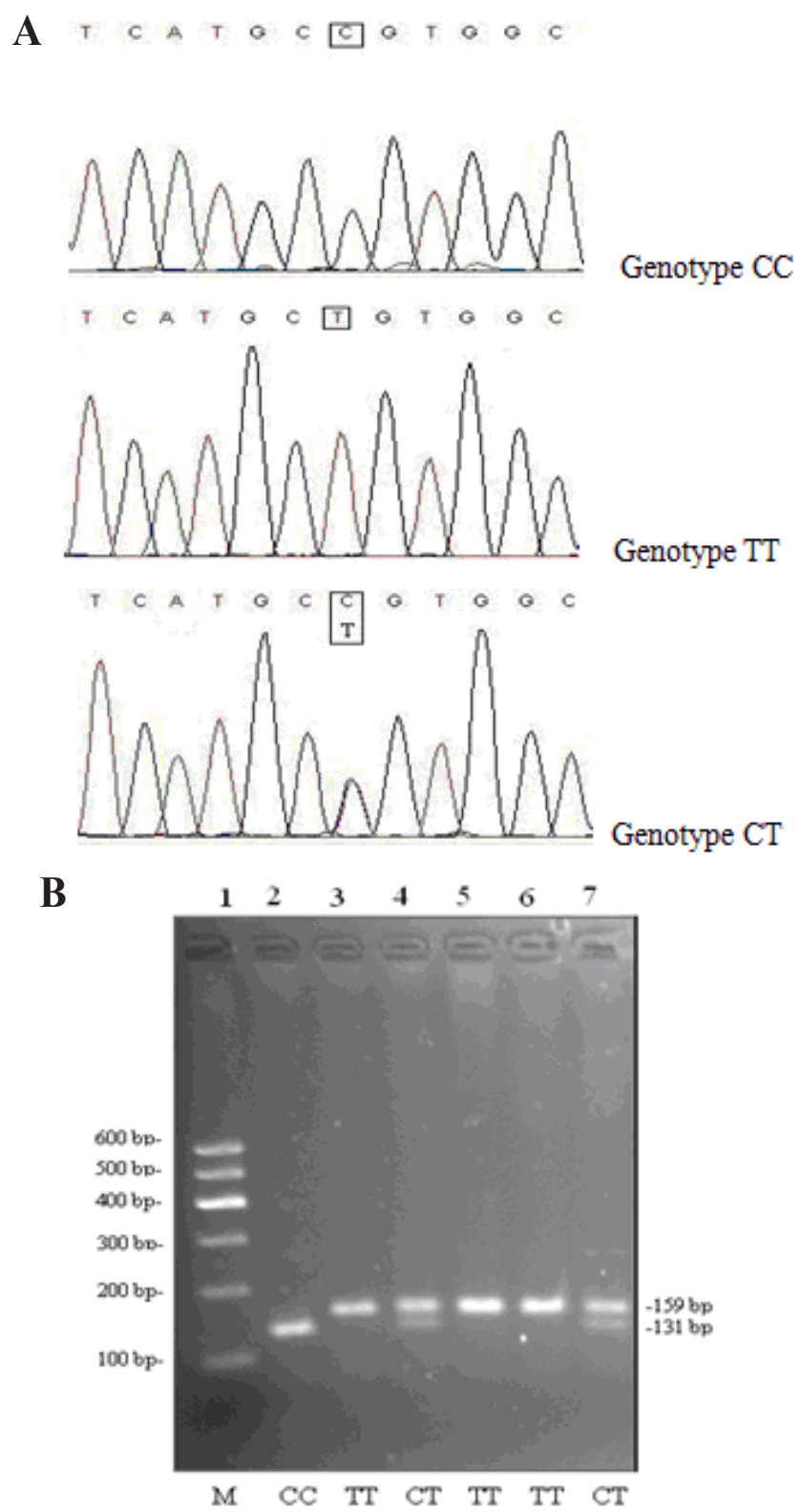

Figure 1. A. Sequencing maps at position of g. $8344 \mathrm{C}>\mathrm{T}$ from different genotypes in the bovine Dapper1 gene. B. Electrophoresis patterns of MspI F-PCR-RFLP analysis of the bovine Dapper 1 gene. TT (159 bp); CT (159+131+28 bp); CC (131+28 bp); lane $M=$ marker I. 
A
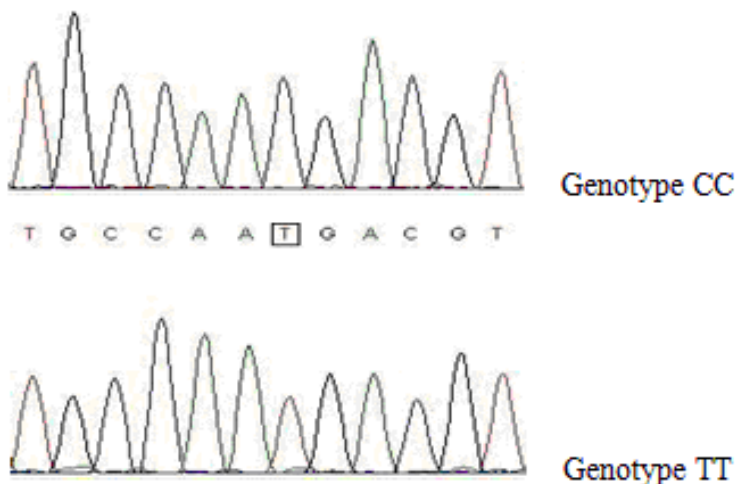

Genotype TT

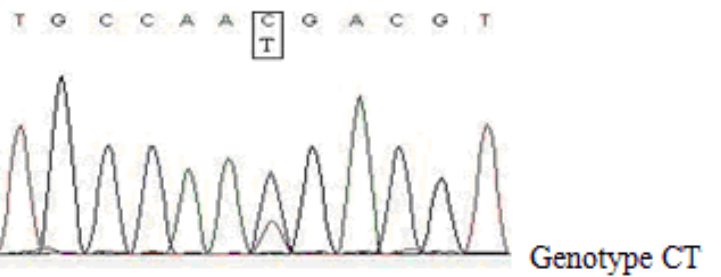

B

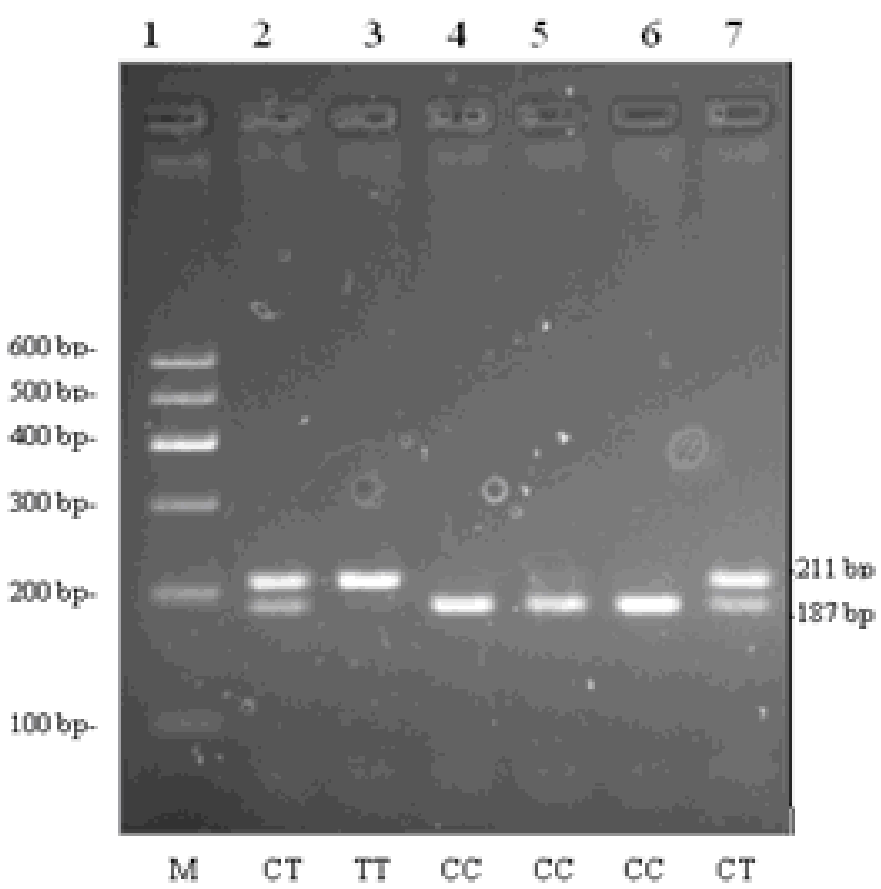

Figure 2. A. Sequencing maps at position of g. $8428 \mathrm{C}>\mathrm{T}$ from different genotypes in the bovine Dapperlgene. B. Electrophoresis patterns of HindII F-PCR-RFLP analysis of the bovine Dapper1 gene. TT (211 bp); CT $(211+187+24$ bp); CC (187+24 bp); lane $M=$ marker I. 


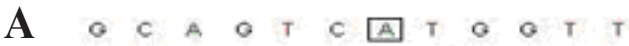
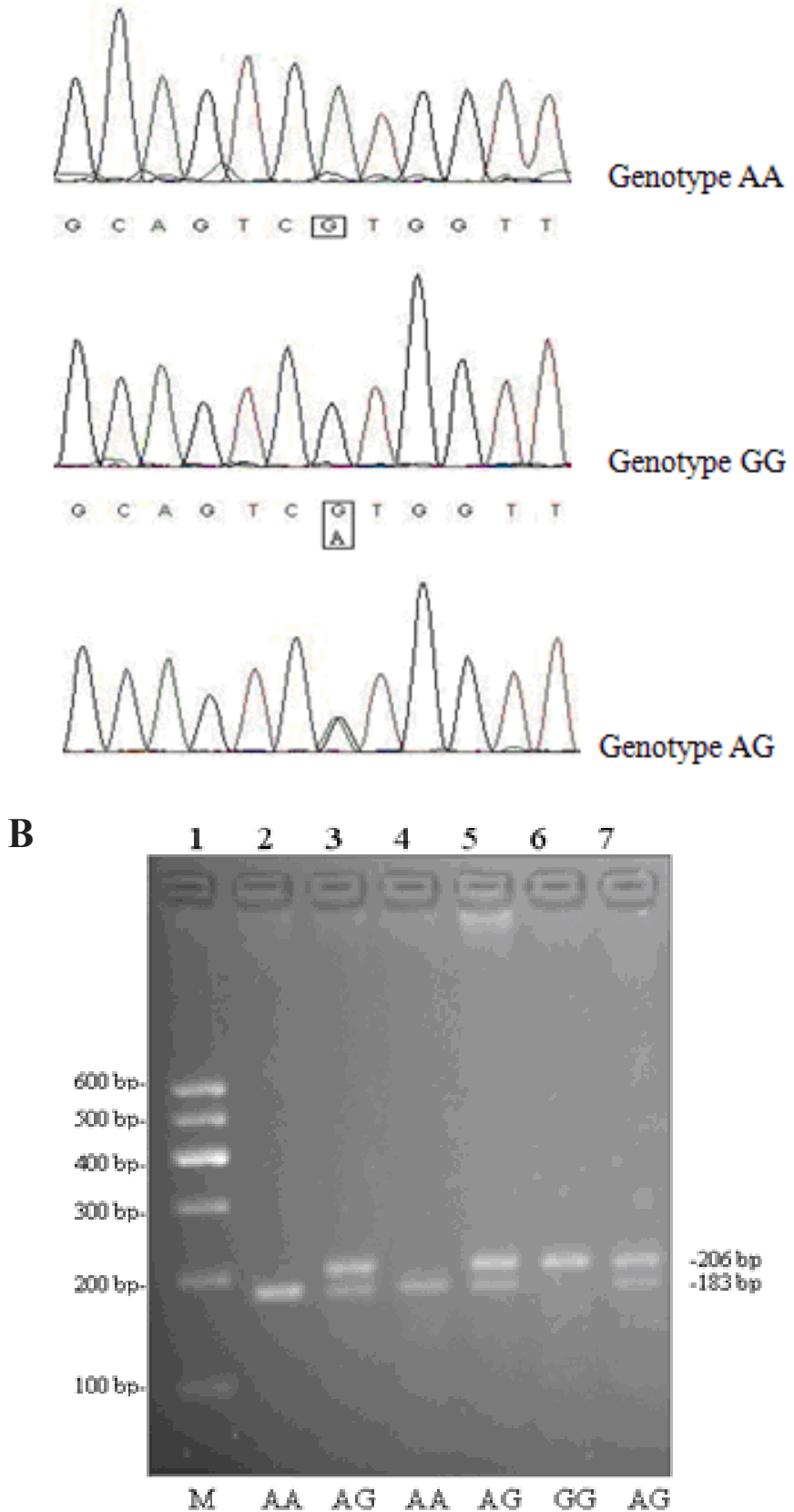

Figure 3. A. Sequencing maps at position of g.10513A $>\mathrm{G}$ from different genotypes in the bovine Dapper 1 gene. B. Electrophoresis patterns of NcoI F-PCR-RFLP analysis of the bovine Dapper1 gene. GG (206 bp); AG $(206+183+23$ bp $)$; AA $(183+23$ bp $)$; lane $M=$ marker I. 


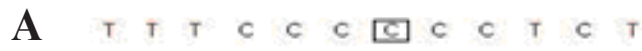
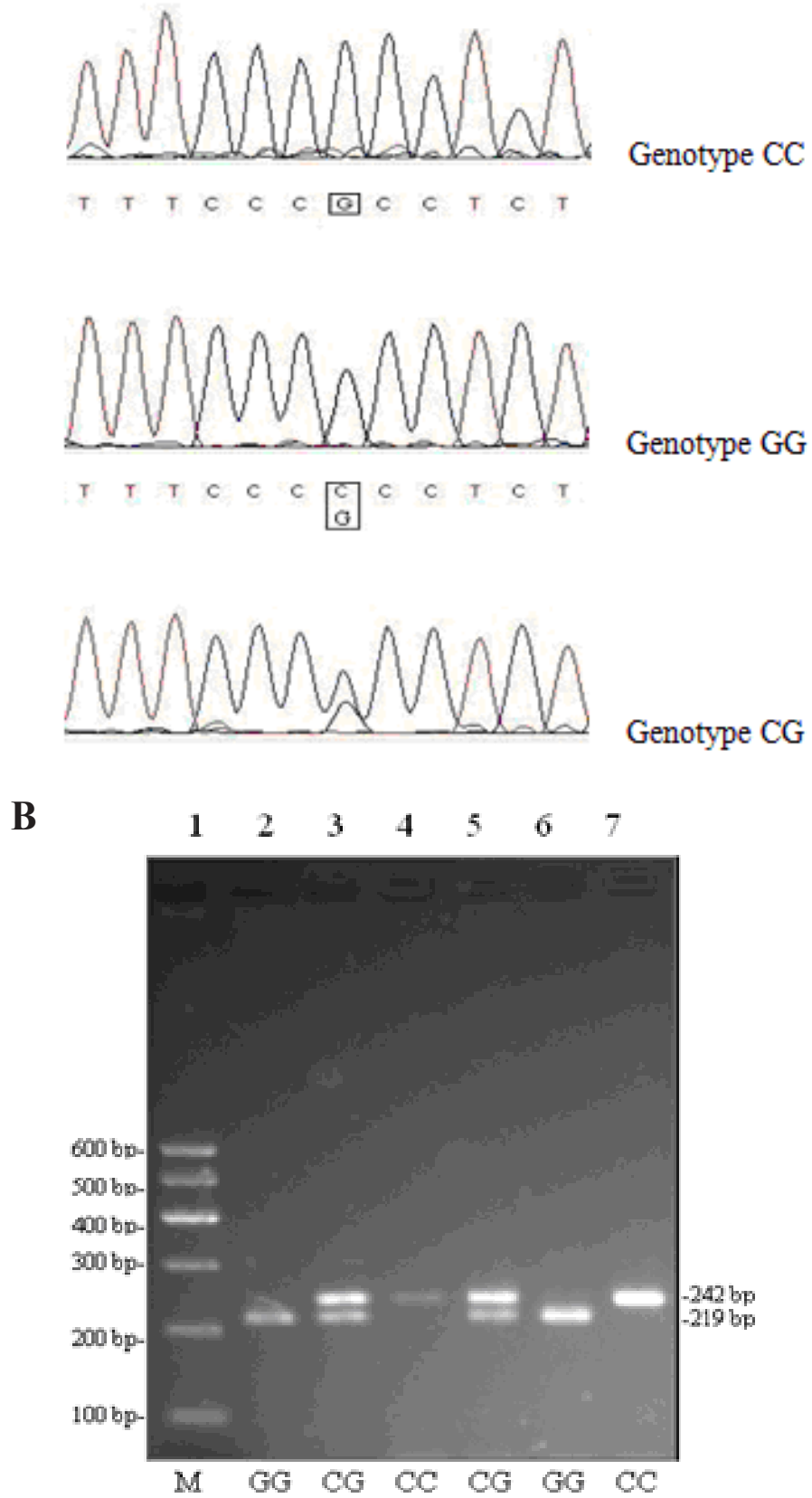

Figure 4. A. Sequencing maps at position of g. $10765 \mathrm{C}>\mathrm{G}$ from different genotypes in the bovine Dapper1 gene. B. Electrophoresis patterns of HhaI F-PCR-RFLP analysis of the bovine Dapper1 gene. CC (242 bp); CG $(242+219+23$ bp); GG (219+23 bp); lane $M=$ marker I. 


\begin{tabular}{|c|c|c|c|c|c|c|}
\hline$\overline{\text { Loci }}$ & Variant type & Location & Alleles & Amino acid change & GenBank accession No. & $\overline{\text { DPS (nt) }}$ \\
\hline SNP1-MspI & g. $8344 \mathrm{C}>\mathrm{T}$ & Exon 6 & $\mathrm{GCC} / \mathrm{GCT}$ & Ala 340 Ala & rs410759551 & 0 \\
\hline SNP2-HindII & g. $8428 \mathrm{C}>\mathrm{T}$ & Exon 6 & $\mathrm{AA} \underline{\mathrm{C}} / \mathrm{AAT}$ & Asn 368 Asn & rs410759552 & 84 \\
\hline SNP3-NcoI & g. $10513 \mathrm{~A}>\mathrm{G}$ & 3'-UTR & - & - & rs410759553 & 2085 \\
\hline SNP4-HhaI & g. $10765 \mathrm{C}>\mathrm{G}$ & 3'-UTR & - & - & rs410759554 & 252 \\
\hline
\end{tabular}

$\overline{\mathrm{DPS}}=$ distance from the previous sequence variant.

Table 3. Genotypic and allelic frequencies (\%), value of the $\chi^{2}$ test, and diversity parameters of the Dapper 1 gene in 5 cattle breeds.

\begin{tabular}{|c|c|c|c|c|c|c|c|c|c|c|c|}
\hline \multirow{2}{*}{$\frac{\text { Loci }}{\text { SNP1-MspI locus }}$} & \multirow[t]{2}{*}{ Breeds } & \multicolumn{4}{|c|}{ Genotype number and frequencies } & \multicolumn{3}{|c|}{ Allelic frequencies } & \multicolumn{3}{|c|}{ Genetic diversity parameters } \\
\hline & & $\mathrm{CC}$ & $\mathrm{CT}$ & TT & Total & $\mathrm{C}$ & $\mathrm{T}$ & $H_{\mathrm{O}}$ & $H_{\mathrm{E}}$ & $N_{\mathrm{E}}$ & PIC \\
\hline & JX & $\begin{array}{c}67 \\
(0.189)\end{array}$ & $\begin{array}{c}194 \\
(0.546)\end{array}$ & $\begin{array}{c}94 \\
(0.265)\end{array}$ & 355 & 0.462 & 0.538 & 0.503 & 0.497 & 1.988 & 0.374 \\
\hline & $\mathrm{CY}$ & $\begin{array}{c}121 \\
(0.515)\end{array}$ & $\begin{array}{c}95 \\
(0.404)\end{array}$ & $\begin{array}{c}19 \\
(0.081)\end{array}$ & 235 & 0.717 & 0.283 & 0.594 & 0.406 & 1.683 & 0.323 \\
\hline & QC & $\begin{array}{c}23 \\
(0.106)\end{array}$ & $\begin{array}{c}143 \\
(0.662)\end{array}$ & $\begin{array}{c}50 \\
(0.232)\end{array}$ & 216 & 0.437 & 0.563 & 0.508 & 0.492 & 1.968 & 0.371 \\
\hline & NY & $\begin{array}{c}33 \\
(0.155)\end{array}$ & $\begin{array}{c}133 \\
(0.624)\end{array}$ & $\begin{array}{c}47 \\
(0.221)\end{array}$ & 213 & 0.467 & 0.533 & 0.502 & 0.498 & 1.991 & 0.374 \\
\hline & LX & $\begin{array}{c}23 \\
(0.139)\end{array}$ & $\begin{array}{c}107 \\
(0.645)\end{array}$ & $\begin{array}{c}36 \\
(0.216)\end{array}$ & 166 & 0.461 & 0.539 & 0.503 & 0.497 & 1.988 & 0.373 \\
\hline \multirow[t]{5}{*}{ SNP2-HindII locus } & JX & $\begin{array}{c}\mathrm{CC} \\
245 \\
(0.690)\end{array}$ & $\begin{array}{c}\text { CT } \\
102 \\
(0.287)\end{array}$ & $\begin{array}{c}\mathrm{TT} \\
8 \\
(0.023)\end{array}$ & $\begin{array}{l}\text { Total } \\
355\end{array}$ & $\begin{array}{c}\mathrm{C} \\
0.834\end{array}$ & $\begin{array}{c}\mathrm{T} \\
0.166\end{array}$ & $\begin{array}{c}H_{\mathrm{O}} \\
0.720\end{array}$ & $\begin{array}{c}H_{\mathrm{E}} \\
0.280\end{array}$ & $\begin{array}{c}N_{\mathrm{E}} \\
1.389\end{array}$ & $\begin{array}{c}\text { PIC } \\
0.241\end{array}$ \\
\hline & $\mathrm{CY}$ & $\begin{array}{c}31 \\
(0.132)\end{array}$ & $\begin{array}{c}139 \\
(0.591)\end{array}$ & $\begin{array}{c}65 \\
(0.277)\end{array}$ & 235 & 0.428 & 0.572 & 0.510 & 0.490 & 1.959 & 0.370 \\
\hline & QC & $\begin{array}{c}48 \\
(0.222)\end{array}$ & $\begin{array}{c}136 \\
(0.630)\end{array}$ & $\begin{array}{c}32 \\
(0.148)\end{array}$ & 216 & 0.537 & 0.463 & 0.503 & 0.497 & 1.989 & 0.374 \\
\hline & NY & $\begin{array}{c}105 \\
(0.493)\end{array}$ & $\begin{array}{c}101 \\
(0.474)\end{array}$ & $\begin{array}{c}7 \\
(0.033)\end{array}$ & 213 & 0.730 & 0.270 & 0.606 & 0.394 & 1.651 & 0.316 \\
\hline & LX & $\begin{array}{c}88 \\
(0.530)\end{array}$ & $\begin{array}{c}69 \\
(0.416)\end{array}$ & $\begin{array}{c}9 \\
(0.054)\end{array}$ & 166 & 0.738 & 0.262 & 0.613 & 0.387 & 1.631 & 0.312 \\
\hline \multirow[t]{5}{*}{ SNP3-NcoI locus } & $\mathrm{JX}$ & $\begin{array}{c}\text { AA } \\
57 \\
(0.161)\end{array}$ & $\begin{array}{c}\mathrm{AG} \\
202 \\
(0.569)\end{array}$ & $\begin{array}{c}\mathrm{GG} \\
96 \\
(0.270)\end{array}$ & $\begin{array}{l}\text { Total } \\
355\end{array}$ & $\begin{array}{c}\text { A } \\
0.445\end{array}$ & $\begin{array}{c}\mathrm{G} \\
0.555\end{array}$ & $\begin{array}{c}H_{\mathrm{O}} \\
0.506\end{array}$ & $\begin{array}{c}H_{\mathrm{E}} \\
0.494\end{array}$ & $\begin{array}{c}N_{\mathrm{E}} \\
1.976\end{array}$ & $\begin{array}{c}\text { PIC } \\
0.372\end{array}$ \\
\hline & $\mathrm{CY}$ & $\begin{array}{c}120 \\
(0.511)\end{array}$ & $\begin{array}{c}106 \\
(0.451)\end{array}$ & $\begin{array}{c}9 \\
(0.038)\end{array}$ & 235 & 0.736 & 0.264 & 0.612 & 0.388 & 1.635 & 0.313 \\
\hline & QC & $\begin{array}{c}34 \\
(0.157)\end{array}$ & $\begin{array}{c}130 \\
(0.602)\end{array}$ & $\begin{array}{c}52 \\
(0.241)\end{array}$ & 216 & 0.458 & 0.542 & 0.503 & 0.497 & 1.986 & 0.373 \\
\hline & NY & $\begin{array}{c}27 \\
(0.127)\end{array}$ & $\begin{array}{c}135 \\
(0.634)\end{array}$ & $\begin{array}{c}51 \\
(0.239)\end{array}$ & 213 & 0.444 & 0.556 & 0.506 & 0.494 & 1.975 & 0.372 \\
\hline & LX & $\begin{array}{c}17 \\
(0.102)\end{array}$ & $\begin{array}{c}99 \\
(0.596)\end{array}$ & $\begin{array}{c}50 \\
(0.302)\end{array}$ & 166 & 0.401 & 0.599 & 0.520 & 0.480 & 1.924 & 0.365 \\
\hline \multirow[t]{6}{*}{ SNP4-HhaI locus } & & $\mathrm{CC}$ & $\mathrm{CG}$ & GG & Total & $\mathrm{C}$ & $\mathrm{G}$ & $H_{\mathrm{O}}$ & $H_{\mathrm{E}}$ & $N_{\mathrm{E}}$ & PIC \\
\hline & JX & $\begin{array}{c}106 \\
(0.298)\end{array}$ & $\begin{array}{c}157 \\
(0.442)\end{array}$ & $\begin{array}{c}92 \\
(0.260)\end{array}$ & 355 & 0.519 & 0.481 & 0.501 & 0.499 & 1.997 & 0.375 \\
\hline & $\mathrm{CY}$ & $\begin{array}{c}218 \\
(0.928)\end{array}$ & $\begin{array}{c}17 \\
(0.072)\end{array}$ & $\begin{array}{c}0 \\
(0.000)\end{array}$ & 235 & 0.964 & 0.036 & 0.930 & 0.070 & 1.075 & 0.067 \\
\hline & QC & $\begin{array}{c}99 \\
(0.458)\end{array}$ & $\begin{array}{c}90 \\
(0.417)\end{array}$ & $\begin{array}{c}27 \\
(0.125)\end{array}$ & 216 & 0.667 & 0.333 & 0.559 & 0.441 & 1.79 & 0.344 \\
\hline & NY & $\begin{array}{c}65 \\
(0.305)\end{array}$ & $\begin{array}{c}113 \\
(0.531)\end{array}$ & $\begin{array}{c}35 \\
(0.164)\end{array}$ & 213 & 0.570 & 0.430 & 0.510 & 0.490 & 1.961 & 0.370 \\
\hline & LX & $\begin{array}{c}56 \\
(0.337)\end{array}$ & $\begin{array}{c}81 \\
(0.488)\end{array}$ & $\begin{array}{c}29 \\
(0.175)\end{array}$ & 166 & 0.581 & 0.419 & 0.513 & 0.487 & 1.948 & 0.368 \\
\hline
\end{tabular}

$\mathrm{JX}=$ Jiaxian red cattle $(\mathrm{N}=355) ; \mathrm{CY}=$ Caoyuan red cattle $(\mathrm{N}=235) ; \mathrm{QC}=$ Qinchuan cattle $(\mathrm{N}=216) ; \mathrm{NY}=$ Nanyang cattle $(\mathrm{N}=213) ; \mathrm{LX}=$ Luxi cattle $(\mathrm{N}=166) ; H_{\mathrm{O}}=$ observed and $H_{\mathrm{E}}=$ expected heterozygosities; $N_{\mathrm{E}}=$ effective number of alleles; $\mathrm{PIC}=$ polymorphic information content. 
The PIC value is effective for the assessment of genetic diversity at various loci of candidate genes. According to PIC classification, values of the four loci ranged from 0.067 to 0.375 in the 5 cattle populations. The SNP1-MspI (mean PIC value $=0.363$ ) and SNP3-NcoI (mean PIC value $=0.359$ ) loci showed moderate genetic diversity. At the SNP2-HindII locus, only JX cattle showed low polymorphism $(\mathrm{PIC}$ value $=0.241$ ). The PIC value at the SNP4HhaI locus in CY cattle was the lowest (0.067) because of the absence of the GG genotype.

\section{LD and haplotype analysis of bovine Dapper1}

LD among the four SNPs of Dapper1 in the cattle populations is shown in Table 4, which indicates that $D^{\prime}$ values ranged from 0.034 to $0.970 ; r^{2}$ values ranged from 0.000 to 0.764 . For JX cattle, SNP1, SNP3, and SNP4 were closely linked $\left(r^{2}>0.33\right)$, but SNP2 had a low level of LD with the other SNP loci. In the CY population, the level of LD in the 4 SNPs was very low. In QC cattle, only SNP1 and SNP3 were closely linked $\left(r^{2}=0.363\right)$; SNP2 and SNP4 had the smallest $r^{2}$ value (0.000). In the NY and LX populations, SNP1 and SNP3, SNP1 and SNP4, SNP2 and SNP3, and SNP3 and SNP4 were linked closely.

\begin{tabular}{|c|c|c|c|c|c|c|c|c|c|c|}
\hline \multirow[t]{2}{*}{ SNPs } & \multicolumn{2}{|c|}{$\mathrm{JX}$} & \multicolumn{2}{|c|}{ CY } & \multicolumn{2}{|c|}{ QC } & \multicolumn{2}{|c|}{ NY } & \multicolumn{2}{|c|}{ LX } \\
\hline & $r$ & $D^{\prime}$ & $r^{2}$ & $D^{\prime}$ & $r^{2}$ & $D^{\prime}$ & $r^{2}$ & $D^{\prime}$ & $r^{2}$ & $D^{\prime}$ \\
\hline $\mathrm{SNP} 1 / 2$ & 0.176 & 0.867 & 0.025 & 0.219 & 0.208 & 0.701 & 0.249 & 0.768 & 0.322 & 0.880 \\
\hline $\mathrm{SNP} 1 / 3$ & 0.764 & 0.933 & 0.118 & 0.361 & 0.363 & 0.639 & 0.621 & 0.826 & 0.530 & 0.823 \\
\hline SNP $1 / 4$ & 0.736 & 0.962 & 0.065 & 0.827 & 0.094 & 0.307 & 0.573 & 0.932 & 0.484 & 0.887 \\
\hline SNP2/3 & 0.170 & 0.804 & 0.002 & 0.069 & 0.207 & 0.746 & 0.408 & 0.938 & 0.365 & 0.829 \\
\hline SNP2/4 & 0.134 & 0.848 & 0.015 & 0.545 & 0.000 & 0.034 & 0.260 & 0.967 & 0.235 & 0.959 \\
\hline SNP3/4 & 0.622 & 0.952 & 0.059 & 0.826 & 0.091 & 0.310 & 0.566 & 0.970 & 0.355 & 0.859 \\
\hline Mean & 0.434 & 0.894 & 0.047 & 0.475 & 0.161 & 0.456 & 0.446 & 0.900 & 0.382 & 0.873 \\
\hline
\end{tabular}

$\overline{\mathrm{SNPs}}=$ estimated values of linkage disequilibrium $\left(r^{2}\right.$ and $\left.D^{\prime}\right)$ between SNP pairs. SNP1 $=$ SNP1-Ms $p$; SNP2 $=$ SNP2-HindII; SNP3 = SNP3-NcoI; SNP4 = SNP4-HhaI. For abbreviations, see legend to Table 3.

Haplotypes were reconstructed in the 5 breeds by using the PHASE program. Sixteen haplotypes were identified (Table 5), of which nine (Hap1, Hap3, Hap5, Hap7, Hap9, Hap1113, and Hap15) were shared among all 5 breeds. One haplotype (Hap2) is unique to QC. Two haplotypes were detected in only 2 breeds: Hap6 is unique to QC and NY, and Hap8 is detected only in CY and QC. Hap4 is absent in CY, and QC cattle lack Hap10. Hap16 was not detected in NY. Hap12 had the highest frequency in JX (0.454), NY (0.413), and LX (0.371). Hap5 had the highest frequency in CY (0.347) and QC (0.245).

\section{Association between individual SNPs and growth traits in NY cattle}

To investigate the effects of SNPs, we analyzed the relationship between Dapper 1 individual SNP genotypes and BW in NY cattle $(\mathrm{N}=213)$ aged $0,6,12,18$, and 24 months. Statistical analyses showed that in SNP1-MspI and SNP3-NcoI loci, homozygous individuals with genotypes CC and AA had significantly higher BW6 than those of homozygous TT and GG genotype animals ( $<<0.05$; Table 6), and individuals with the SNP3-NcoI-AA genotype 
showed higher BW12 than those in individuals with other genotypes $(\mathrm{P}<0.05)$, suggesting that alleles $\mathrm{C}$ and $\mathrm{T}$ have a positive effect on growth performance in very young cattle. This result is consistent with the function of Dapper 1, which plays a central role in embryogenesis.

Table 5. Haplotype and haplotype frequency of four SNPs in the bovine Dapperl gene within the population studied.

\begin{tabular}{|c|c|c|c|c|c|c|c|c|c|}
\hline \multirow[t]{2}{*}{ Haplotypes } & \multicolumn{4}{|c|}{ SNPs } & \multicolumn{5}{|c|}{ Frequency in population } \\
\hline & SNP1 & SNP2 & SNP3 & SNP4 & $\begin{array}{c}J X \\
(\mathrm{~N}=355)\end{array}$ & $\begin{array}{c}\mathrm{CY} \\
(\mathrm{N}=235)\end{array}$ & $\begin{array}{c}\mathrm{QC} \\
(\mathrm{N}=216)\end{array}$ & $\begin{array}{c}N Y \\
(\mathrm{~N}=213)\end{array}$ & $\begin{array}{c}\mathrm{LX} \\
(\mathrm{N}=166)\end{array}$ \\
\hline Hap1 & $\mathrm{C}$ & $\mathrm{C}$ & A & $\mathrm{C}$ & 0.268 & 0.225 & 0.000 & 0.166 & 0.135 \\
\hline Hap2 & $\mathrm{C}$ & C & A & G & & & 0.005 & & \\
\hline Нар3 & C & C & G & C & 0.036 & 0.053 & 0.019 & 0.049 & 0.058 \\
\hline Нар4 & C & C & G & G & 0.006 & & 0.013 & 0.011 & 0.022 \\
\hline Нар5 & C & $\mathrm{T}$ & A & C & 0.143 & 0.347 & 0.245 & 0.233 & 0.228 \\
\hline Hap6 & $\mathrm{C}$ & $\mathrm{T}$ & A & G & & & 0.117 & 0.003 & \\
\hline Нар7 & C & $\mathrm{T}$ & G & C & 0.006 & 0.085 & 0.045 & 0.006 & 0.018 \\
\hline Нар8 & C & $\mathrm{T}$ & G & G & & 0.007 & 0.018 & & \\
\hline Hap9 & $\mathrm{T}$ & $\mathrm{C}$ & A & $\mathrm{C}$ & 0.005 & 0.088 & 0.029 & 0.015 & 0.007 \\
\hline Hap10 & $\mathrm{T}$ & C & A & G & 0.010 & 0.006 & & 0.002 & 0.022 \\
\hline Hap11 & $\mathrm{T}$ & $\mathrm{C}$ & G & $\mathrm{C}$ & 0.057 & 0.033 & 0.088 & 0.073 & 0.123 \\
\hline Hap12 & $\mathrm{T}$ & C & G & G & 0.454 & 0.023 & 0.145 & 0.413 & 0.371 \\
\hline Hap13 & $\mathrm{T}$ & $\mathrm{T}$ & A & C & 0.001 & 0.030 & 0.017 & 0.025 & 0.009 \\
\hline Hap14 & $\mathrm{T}$ & $\mathrm{T}$ & A & G & & & 0.035 & 0.000 & \\
\hline Hap15 & $\mathrm{T}$ & $\mathrm{T}$ & G & $\mathrm{C}$ & 0.005 & 0.103 & 0.018 & 0.004 & 0.004 \\
\hline Hap16 & $\mathrm{T}$ & $\mathrm{T}$ & G & G & 0.010 & 0.000 & 0.206 & & 0.004 \\
\hline Number & - & - & - & - & 12 & 12 & 15 & 13 & 12 \\
\hline
\end{tabular}

Table 6. Associations of single and combined SNPs within the Dapperl gene with growth traits in the Nanyang (NY) cattle.

\begin{tabular}{|c|c|c|c|c|c|c|}
\hline \multirow[t]{2}{*}{ Loci } & \multirow[t]{2}{*}{ Genotypes } & \multicolumn{5}{|c|}{ Growth traits (mean $\pm \mathrm{SE}$ ) } \\
\hline & & BW0 (kg) & BW6 (kg) & BW12 (kg) & BW18 (kg) & BW24 (kg) \\
\hline SNP1- & $\mathrm{CC}(\mathrm{N}=33)$ & $30.684 \pm 0.615$ & $166.842 \pm 4.209^{\mathrm{a}}$ & $231.000 \pm 5.411$ & $300.00 \pm 6.94$ & $374.211 \pm 8.516$ \\
\hline \multirow[t]{2}{*}{ locus } & $\mathrm{CT}(\mathrm{N}=133)$ & $30.092 \pm 0.383$ & $160.531 \pm 2.621^{\mathrm{ab}}$ & $221.122 \pm 3.369$ & $301.55 \pm 4.32$ & $362.208 \pm 5.358$ \\
\hline & $\mathrm{TT}(\mathrm{N}=47)$ & $29.596 \pm 0.526$ & $152.615 \pm 3.598^{\mathrm{b}}$ & $220.885 \pm 4.626$ & $296.19 \pm 5.93$ & $375.115 \pm 7.250$ \\
\hline SNP2-HindII & $\mathrm{CC}(\mathrm{N}=105)$ & $30.073 \pm 0.415$ & $158.317 \pm 2.959$ & $223.878 \pm 3.696$ & $295.789 \pm 4.725$ & $365.439 \pm 5.865$ \\
\hline \multirow[t]{2}{*}{ locus } & $\mathrm{CT}(\mathrm{N}=101)$ & $29.840 \pm 0.388$ & $160.021 \pm 2.963$ & $220.787 \pm 3.452$ & $302.358 \pm 4.467$ & $369.848 \pm 5.537$ \\
\hline & $\mathrm{TT}(\mathrm{N}=7)$ & $31.917 \pm 1.086$ & $165.333 \pm 7.734$ & $235.167 \pm 9.663$ & $307.830 \pm 12.350$ & $375.500 \pm 15.330$ \\
\hline SNP3-NcoI & $\mathrm{AA}(\mathrm{N}=27)$ & $30.526 \pm 0.619$ & $168.737 \pm 4.228^{\mathrm{a}}$ & $232.000 \pm 5.364^{\mathrm{a}}$ & $299.421 \pm 6.934$ & $374.316 \pm 8.586$ \\
\hline \multirow[t]{2}{*}{ locus } & $\operatorname{AG}(\mathrm{N}=135)$ & $29.991 \pm 0.354$ & $157.724 \pm 2.420^{\mathrm{b}}$ & $219.414 \pm 3.070^{\mathrm{b}}$ & $301.328 \pm 3.969$ & $364.982 \pm 4.957$ \\
\hline & $\mathrm{GG}(\mathrm{N}=51)$ & $29.853 \pm 0.654$ & $155.882 \pm 4.470^{\mathrm{b}}$ & $225.471 \pm 5.670^{\mathrm{b}}$ & $294.765 \pm 7.331$ & $372.529 \pm 9.077$ \\
\hline SNP4-HhaI & $\mathrm{CC}(\mathrm{N}=65)$ & $29.878 \pm 0.443$ & $161.162 \pm 3.106$ & $223.541 \pm 3.933$ & $300.297 \pm 4.927$ & $367.135 \pm 6.147$ \\
\hline \multirow[t]{3}{*}{ locus } & $\mathrm{CG}(\mathrm{N}=113)$ & $30.326 \pm 0.411$ & $159.953 \pm 2.881$ & $222.326 \pm 3.648$ & $302.744 \pm 4.570$ & $365.762 \pm 5.769$ \\
\hline & $\mathrm{GG}(\mathrm{N}=35)$ & $29.821 \pm 0.721$ & $154.500 \pm 5.049$ & $224.000 \pm 6.394$ & $289.143 \pm 8.010$ & $378.786 \pm 9.992$ \\
\hline & Diplotype & BW0 (kg) & BW6 (kg) & BW12 (kg) & BW18 (kg) & BW24 (kg) \\
\hline SNP1-MspI- & H1H5 $(\mathrm{N}=23)$ & .0117 & $171.000 \pm$ & $235.778 \pm 7.853$ & $294.898 \pm 10.540$ & $380.889 \pm 12.890$ \\
\hline SNP2-Hind- & $\mathrm{H} 5 \mathrm{H} 5(\mathrm{~N}=15)$ & $32.100 \pm$ & $165.200 \pm 8.495^{\mathrm{ab}}$ & $238.000 \pm 10.535$ & $308.200 \pm 14.141$ & $382.200 \pm 17.294$ \\
\hline SNP3-NcoI- & H1H11 $(\mathrm{N}=17)$ & $30.500 \pm 1.142$ & $151.667 \pm 7.755^{\mathrm{ab}}$ & $216.667 \pm 9.618$ & $304.333 \pm 12.908$ & $356.167 \pm 15.787$ \\
\hline \multirow{4}{*}{ SNP4-HhaI } & $\mathrm{H} 1 \mathrm{H} 12(\mathrm{~N}=28)$ & $30.800 \pm 0.885$ & $166.400 \pm 6.007^{\mathrm{ab}}$ & $229.200 \pm 7.450$ & $296.100 \pm 9.999$ & $358.200 \pm 12.228$ \\
\hline & H5H11 $(\mathrm{N}=21)$ & $30.250 \pm 0.989$ & $162.625 \pm 6.716^{\mathrm{ab}}$ & $219.125 \pm 8.329$ & $306.500 \pm 11.179$ & $354.750 \pm 13.672$ \\
\hline & $\mathrm{H} 5 \mathrm{H} 12(\mathrm{~N}=45)$ & $30.441 \pm 0.679$ & $156.235 \pm 4.60^{7 \mathrm{ab}}$ & $219.765 \pm 5.714$ & $303.529 \pm 7.669$ & $376.941 \pm 9.379$ \\
\hline & $\mathrm{H} 12 \mathrm{H} 12(\mathrm{~N}=30)$ & $29.636 \pm 0.844$ & $150.909 \pm 5.728^{b}$ & $226.000 \pm 7.103$ & $292.909 \pm 9.534$ & $385.455 \pm 11.659$ \\
\hline
\end{tabular}

SE = standard error; BW0 = birth weight; BW6 = body weight of 6 months; BW12 = body weight of 12 months; BW18 = body weight of 18 months; BW24 = body weight of 24 months. LSM in a column with no common superscript letters differ significantly $(\mathrm{P}<0.05)$.

\section{Association between haplotype combinations and growth traits in NY cattle}

To further elucidate the association between diplotypes of the four SNPs and BW in NY cattle, 
we constructed the haplotypes of the SNPs. As shown in Table 5, 13 haplotypes were found in NY cattle. Because the frequenciesy of Hap4 (0.011), Hap6 (0.003), Hap7 (0.006), Hap9 (0.015), Hap10 (0.002), Hap14 (0.000), and Hap15 (0.004) were small, our association analysis for the effect of diplotype excluded their related diplotypes, and percentages of observations that were below $5 \%$ were also excluded. Therefore, 6 haplotypes were analyzed: Hap1 (0.160), Hap3 (0.049), Hap5 (0.233), Hap11 (0.073), and Hap12 (0.413), and 7 diplotypes were used in the correlation analysis (see Table 6). Taken together, the four SNPs displayed consistent significant effects on BW6 with a single SNP. Individuals with H1H5 (CCCTAACC) had higher BW6 than those with other diplotypes, particularly, H12H12 (TTCCGGGG). This difference was significant $(\mathrm{P}<0.05)$. However, significant differences were not found in the other traits in cattle aged $0,12,18$, and 24 months $(\mathrm{P}>0.05)$. These results showed that the combined effects of the four SNPs were consistent with that of a single SNP.

\section{DISCUSSION}

The function of Dapper is evolutionally conserved in fish and mammals ( $\mathrm{Su}$ et al., 2007), and studies have found that Dapperl is required to induce Wnt/ $\beta$-catenin target genes and enhance the activity of Wnt/ $\beta$-catenin in zebrafish (Waxman et al., 2004). Because the Wnt signaling pathway plays an important role in embryogenesis (Gao et al., 2008), Dapper 1 may be associated with growth in cattle.

The present study is the first to report on the polymorphism of bovine Dapper1. Four SNPs (NC_007308.4: g.8344C > T, g.8428C > T, g.10513A $>$ G, and g.10765C $>$ G) were detected in 5 Chinese cattle breeds. The first two were synonymous mutations located in exon 6 , and the latter two were located in the 3'-UTR; hence, to a certain degree, this gene is conservative. These findings are consistent with the function of the evolutionally conserved Dapper protein (Su et al., 2007).

Of particular interest, no CY individual had a GG genotype in the SNP4-HhaI locus (see Table 3), likely because first, the number of CY cattle was limited, and therefore, we may have excluded individuals with the GG genotype from our CY cattle population; and second, different selection purposes and histories have led to the disappearance of CY individuals with the GG genotype at this locus. These results are consistent with those of our previous studies (Wang et al., 2010; Xu et al., 2011). For example, Xu et al. (2011) found that at the P7 locus of the paired box 7 gene, only two genotypes occur in CY cattle. In the absence of the GG genotype, $N_{\mathrm{E}}$ value in this locus approached 1 , and the PIC value was $<0.25$. Consistent with PIC classification, this locus in CY cattle shows low polymorphism.

The $r^{2}$ value of SNP2 and SNP4 in QC cattle is 0.000 (see Table 4), meaning that these SNPs are not linked. Table 5 shows that QC cattle have the greatest number of haplotypes. For CY cattle, the mean $r^{2}$ value is the smallest (0.047), indicating that the four SNPs in this breed experienced the least LD, and possibly, recombination will be high and LD will be low in genovariation-dense regions.

Naturally occurring silent mutations have been found to change the function of protein - that is, protein products with the same aa sequence but different gene sequences had different structural and functional properties (Komar, 2007; Kweekel et al., 2009). For example, a silent polymorphism in multi-drug resistance gene-1 results in a substrate specificity change (Kimchi-Sarfaty et al., 2007). In our research, the g.8344C $>$ T mutations at the SNP1-MspI locus were synonymous, but the CC genotype was associated with higher BW6 than that of the TT genotype, a result consistent with other findings. 
Although located in the 3'-UTR, the mutation g.10513A $>\mathrm{G}$ at the SNP3-NcoI locus may not be a causal mutation. Instead, it may regulate the expression of Dapperl because 3'-UTR sequences can affect the mechanism of mRNA deadenylation and degradation (Xu et al., 1997, 1998). Therefore, the 3'-UTR mutation may directly or indirectly influence the stability of Dapper 1 mRNA.

$\mathrm{BW}$ is one of the growth traits, which are complex, quantitative traits regulated by various genes involved in many physiological activities. For each candidate gene, growth traits were affected not only by the single SNP but also by SNP-SNP interaction; therefore, the association analysis between the combined SNPs has important biological value (Lango et al., 2008). In this study, the association analysis between the combined SNPs with growth traits was consistent with the association analysis in a single SNP. In single SNP analysis, the SNP1-MspI-CC and SNP3-NcoI-AA genotypes were advantageous for BW6, and the combination of genotype H1H5 (CCCTAACC) showed better performance for BW6. Specifically, the genotype of the SNP1-MspI locus in the H1H5 diplotype was CC and the genotype of the SNP3-NcoI locus in the H1H5 diplotype was AA.

To summarize, we first reported four SNPs in bovine Dapper 1, 2 of which (g.8344C $>$ T and g. 10513A $>$ G) had significant effects on BW6 in NY cattle. The combination of SNPs had an effect consistent with that of a single SNP; hence, it was assumed that alleles $\mathrm{C}$ and A were responsible for the positive effect on growth performance in very young cattle. Therefore, the $\mathrm{CC}$ and AA genotypes should be selected in the breeding schemes of cattle. This study may contribute to evaluations of these genotypes as genetic markers in bovine breeding. Further studies, such as functional analysis, are needed to fully elucidate how these gene mutations may affect Dapper 1 activity and whether they are appropriate as candidate markers associated with whole energy metabolism in cattle.

\section{ACKNOWLEDGMENTS}

Research supported by the National Natural Science Foundation of China (Grant \#30972080 and \#31272408), the Program of National Beef Cattle Industrial Technology System (Grant \#CARS-38), the Basic and Foreland Technology Study Program of Henan Province (Grant \#072300430160), and the Agricultural Science and Technology Innovation Projects of Shaanxi Province (\#2012NKC01-13).

\section{REFERENCES}

Barrett JC, Fry B, Maller J and Daly MJ (2005). Haploview: analysis and visualization of LD and haplotype maps. Bioinformatics 21: 263-265.

Cerpa W, Toledo EM, Varela-Nallar L and Inestrosa NC (2009). The role of Wnt signaling in neuroprotection. Drug News Perspect. 22: 579-591.

Cheyette BN, Waxman JS, Miller JR, Takemaru K, et al. (2002). Dapper, a Dishevelled-associated antagonist of betacatenin and JNK signaling, is required for notochord formation. Dev. Cell 2: 449-461.

Dale RM, Sisson BE and Topczewski J (2009). The emerging role of Wnt/PCP signaling in organ formation. Zebrafish 6: 9-14.

Fisher DA, Kivimae S, Hoshino J, Suriben R, et al. (2006). Three Dact gene family members are expressed during embryonic development and in the adult brains of mice. Dev. Dyn. 235: 2620-2630.

Fukuda T, Kokabu S, Ohte S, Sasanuma H, et al. (2010). Canonical Wnts and BMPs cooperatively induce osteoblastic differentiation through a GSK3beta-dependent and beta-catenin-independent mechanism. Differentiation 80: 46-52.

Gao X, Wen J, Zhang L, Li X, et al. (2008). Dapper1 is a nucleocytoplasmic shuttling protein that negatively modulates Wnt signaling in the nucleus. J. Biol. Chem. 283: 35679-35688. 
Gloy J, Hikasa H and Sokol SY (2002). Frodo interacts with Dishevelled to transduce Wnt signals. Nat. Cell Biol. 4: 351-357.

Katoh M and Katoh M (2003). Identification and characterization of human DAPPER1 and DAPPER2 genes in silico. Int. J. Oncol. 22: 907-913.

Kawai M, Mushiake S, Bessho K, Murakami M, et al. (2007). Wnt/Lrp/beta-catenin signaling suppresses adipogenesis by inhibiting mutual activation of PPARgamma and C/EBPalpha. Biochem. Biophys. Res. Commun. 363: 276-282.

Kimchi-Sarfaty C, Oh JM, Kim IW, Sauna ZE, et al. (2007). A "silent" polymorphism in the MDR1 gene changes substrate specificity. Science 315: 525-528.

Komar AA (2007). Silent SNPs: impact on gene function and phenotype. Pharmacogenomics 8: 1075-1080.

Kweekel DM, Antonini NF, Nortier JW, Punt CJ, et al. (2009). Explorative study to identify novel candidate genes related to oxaliplatin efficacy and toxicity using a DNA repair array. Br. J. Cancer 101: 357-362.

Lango H, Palmer CN, Morris AD, Zeggini E, et al. (2008). Assessing the combined impact of 18 common genetic variants of modest effect sizes on type 2 diabetes risk. Diabetes 57: 3129-3135.

Marty A, Amigues Y, Servin B, Renand G, et al. (2010). Genetic variability and linkage disequilibrium patterns in the bovine DNAJA1 gene. Mol. Biotechnol. 44: 190-197.

Mullenbach R, Lagoda PJ and Welter C (1989). An efficient salt-chloroform extraction of DNA from blood and tissues. Trends Genet. 5: 391.

Nei M and Roychoudhury AK (1974). Sampling variances of heterozygosity and genetic distance. Genetics 76: 379-390.

Sham P, Bader JS, Craig I, O’Donovan M, et al. (2002). DNA Pooling: a tool for large-scale association studies. Nat. Rev. Genet. 3: 862-871.

Stephens M, Smith NJ and Donnelly P (2001). A new statistical method for haplotype reconstruction from population data. Am. J. Hum. Genet. 68: 978-989.

Su Y, Zhang L, Gao X, Meng F, et al. (2007). The evolutionally conserved activity of Dapper2 in antagonizing TGF-beta signaling. FASEB J. 21: 682-690.

Tee JM, van Rooijen C, Boonen R and Zivkovic D (2009). Regulation of slow and fast muscle myofibrillogenesis by Wnt/ beta-catenin and myostatin signaling. PLoS One 4: e5880.

Wang J, Li ZJ, Lan XY, Hua LS, et al. (2010). Two novel SNPs in the coding region of the bovine PRDM16 gene and its associations with growth traits. Mol. Biol. Rep. 37: 571-577.

Waxman JS, Hocking AM, Stoick CL and Moon RT (2004). Zebrafish Dapper1 and Dapper2 play distinct roles in Wntmediated developmental processes. Development 131: 5909-5921.

Xu N, Chen CY and Shyu AB (1997). Modulation of the fate of cytoplasmic mRNA by AU-rich elements: key sequence features controlling mRNA deadenylation and decay. Mol. Cell Biol. 17: 4611-4621.

Xu N, Loflin P, Chen CY and Shyu AB (1998). A broader role for AU-rich element-mediated mRNA turnover revealed by a new transcriptional pulse strategy. Nucleic Acids Res. 26: 558-565.

Xu Y, Liu J, Lan X, Zhang Y, et al. (2011). Consistent effects of single and combined SNP(s) within bovine paired box 7 gene (Pax7) on growth traits. J. Genet. 90: e53-e57.

Zhang L, Gao X, Wen J, Ning Y, et al. (2006). Dapper 1 antagonizes Wnt signaling by promoting dishevelled degradation. J. Biol. Chem. 281: 8607-8612.

Zhao H, Nettleton D and Dekkers JCM (2007). Evaluation of linkage disequilibrium measures between multi-allelic markers as predictors of linkage disequilibrium between single nucleotide polymorphisms. Genet. Res. 89: 1-6. 